\title{
Agitation in Dementia: Real-World Impact and Burden on Patients and the Healthcare System
}

\author{
Eddie Jones $^{\mathrm{a}}$, Myrlene Sanon Aigbogun ${ }^{\mathrm{b}}$, James Pike ${ }^{\mathrm{a}}$, Mia Berry ${ }^{\mathrm{a}}$, \\ Christy R. Houle ${ }^{\mathrm{c}}$ and Joseph Husbands ${ }^{\mathrm{a}, *}$ \\ a Adelphi Real World, Bollington, UK \\ ${ }^{\mathrm{b}}$ Otsuka Pharmaceutical Development \& Commercialization Inc., Princeton, NJ, USA \\ ${ }^{\mathrm{c}}$ Lundbeck, Chicago, IL, USA
}

Accepted 5 June 2021

Pre-press 8 July 2021

\begin{abstract}
.
Background: At least $90 \%$ of patients with dementia experience behavioral or neuropsychiatric symptoms including agitation, psychotic symptoms, apathy, depression, and sleep disturbances. Agitation has been reported to be experienced by $60 \%$ of patients with mild cognitive impairment and $76 \%$ of patients with Alzheimer's disease.

Objective: We aimed to assess the impact of agitation in patients with dementia on healthcare resource utilization (HCRU) and healthcare costs.

Methods: This was a retrospective analysis of physician-reported patient data from a point-in-time survey. Patients included were aged $\geq 50$ years, with early cognitive impairment or dementia. Agitated and non-agitated patients were compared. Regression analyses assessed the relationship of agitation score (calculated from number/severity of agitation symptoms) with outcomes, with covariates including age and Mini-Mental State Examination score. Sensitivity analyses compared patients with 0 and $\geq 2$ agitation symptoms following propensity score matching on the base-case covariates.

Results: Data were included for 1,349 patients (agitated, $n=693$; non-agitated, $n=656$ ). Based on regression analyses, agitation score was correlated with proportion of patients with professional caregivers $(p<0.01)$, institutionalized $(p<0.01)$, hospitalized in a psychiatric ward $(p<0.05)$, and receiving an antipsychotic/antidepressant (both $p<0.001$ ); number of consultations with a healthcare professional (HCP), psychiatrist, or psycho-geriatrician; number and cost of hospitalizations $(p<0.01)$; cost of HCP consultations $(p<0.001)$; and total direct healthcare costs $(p<0.001)$. Sensitivity analyses generally supported the base-case analysis.

Conclusion: Agitation in dementia is associated with increased HCRU and healthcare costs. Effective therapies are needed to address agitation in dementia, with the potential to alleviate patient impact, HCRU, and healthcare costs.

Keywords: Agitation, behavioral symptoms, cognitive dysfunction, cost of illness, cross-sectional studies, dementia, health care costs, institutionalization, real-world, referral and consultation, therapeutics
\end{abstract}

\section{INTRODUCTION}

Behavioral or neuropsychiatric symptoms are experienced by more than $90 \%$ of patients with

${ }^{*}$ Correspondence to: Joseph Husbands, Project Manager, Adelphi Real World, Bollington, UK. Tel.: +44 1625 578653; E-mail: joseph.husbands@adelphigroup.com. dementia at some point in the course of their disease $[1,2]$; these include agitation, psychotic symptoms (hallucinations and delusions), apathy, depression, and sleep disturbances [3]. The prevalence of agitation has been reported to be $60 \%$ in patients with mild cognitive impairment (CI) and 76\% in those with Alzheimer's disease (AD) [4]. A systematic review reported that the proportion of patients with agitation 
symptoms increase slightly or remain stable over the course of dementia, but that agitation severity ratings increase over time [5].

Despite the high prevalence of agitation in patients with dementia, its consideration as a distinct entity has been poor [6]. Until recently, there was no widespread agreement on what elements comprise agitation or its definition. In 2015, the International Psychogeriatric Association (IPA) published a provisional consensus on the definition of agitation: 1) occurring in patients with a CI or dementia syndrome; 2) exhibiting behavior consistent with emotional distress; 3) manifesting excessive motor activity, verbal aggression, or physical aggression; and 4) evidencing behaviors that cause excess disability and are not solely attributable to another disorder [7].

Agitation and aggression in AD have been shown to be associated with reductions in cholinergic and serotonergic markers [8]; and while treatments that are known to affect relevant pathways are commonly used, there is currently no Food and Drug Administration-approved pharmacologic treatment for agitation in dementia [9]. Pharmacologic treatments currently prescribed for dementia-associated agitation include antipsychotics, antidepressants, anticonvulsants, anxiolytics, and acetylcholinesterase inhibitors [10]. The 2016 American Psychiatric Association Practice Guidelines recommend a comprehensive personalized treatment plan, including non-pharmacologic and pharmacologic interventions, with antipsychotics recommended when agitation symptoms are severe [9].

Agitation has been reported to adversely affect patient care, increasing the chances of institutionalization and impacting the quality of life of patients $[6,7]$. Furthermore, a systematic review of literature revealed a paucity of data on the economic burden of agitation in dementia [11]. Therefore, the objective of this study was to assess the impact and burden of agitation in dementia on patients and the healthcare system.

\section{MATERIALS AND METHODS}

\section{Data source}

This was a retrospective analysis of United States (US) data drawn from the 2015/16 Adelphi Real World Dementia Disease Specific Programme $(\mathrm{DSP})^{\mathrm{TM}}$, a real-world, point-in-time survey of physicians and their consulting patients.
Full details of the DSP methodology [12] and methods specific to the Dementia DSP [13] have been published previously. In brief, primary care physicians (PCPs) and specialists managing patients with neurodegenerative diseases from across the US were identified from publicly available lists of healthcare professionals (HCPs). They were invited to participate in the DSPTM and were included if they met eligibility criteria [13]. Physicians reported data about their practice, including total patient number under their care and number of $\mathrm{CI} /$ dementia patients diagnosed within the past 12 months, and completed a record form for the next nine consecutively consulting patients with $\mathrm{CI} /$ dementia.

\section{Sample selection}

Patients were eligible for inclusion in this analysis if they were aged $\geq 50$ years with early $\mathrm{CI}, \mathrm{AD}$ or mixed dementia (vascular/AD). Patients with dementia of purely vascular origin or due to environmental factors (e.g., traumatic head injury or alcoholism) were excluded.

\section{Outcomes}

Data provided by physicians included patient demographics, history/diagnosis, CI/dementia symptoms and treatments, concomitant conditions and treatments, presence of a professional or non-professional caregiver, caregiver hours/week, HCP consultation, and hospitalization history.

\section{Healthcare costs}

Direct medical costs related to professional caregiving, nursing home costs, HCP consultations, hospitalizations, treatment and scans in the previous 12 months were calculated as US\$/year, based on reported healthcare resource utilization (HCRU) multiplied by unit costs. Given the lack of nationally representative healthcare costs for the US, unit costs were derived from a number of sources. HCP consultation costs were derived from data reported by the American Academy of Neurology, Centers for Disease Control and Prevention, and Centers for Medicare \& Medicaid Services [14-16], the unit cost per hospital stay was taken from the Agency for Healthcare Research and Quality website [17], cost of scans was drawn from the New Choice Health website [18] and medication costs were derived from the US Department of Veterans Affairs National Acquisition Center cost database [19]. 
Analysis

Descriptive analyses were performed with patients considered agitated if they displayed $\geq 1$ of seven agitation-related physician-reported symptoms, namely: aggression, disinhibition, wandering, agitation, irritability/lability, aberrant motor behavior, or social interaction problems (thus reflecting elements of the IPA consensus on the definition of agitation [7]); patients were regarded as non-agitated if they demonstrated none of these symptoms.

An overall agitation score was derived based on the same seven symptoms. Physicians rated each symptom as not present ( 0$)$, mild (1), moderate (2) or severe (3), and scores were summed to provide a score between 0 (no symptoms) and 21 (all severe symptoms). It should be noted that this scoring method assumes all symptoms are of equal consequence and that there is a linear relationship between mild, moderate, and severe symptom severity, and is not a recognized tool for assessing agitation. Multiple regression analyses were conducted with selected outcomes as the dependent variable and agitation score as the main independent variable of interest. Other regression covariates adjusted for were age, gender, time since diagnosis, Mini-Mental State Examination (MMSE) score, and the number of activities of daily living (ADLs) with which they needed help. Standard errors in regressions were adjusted for possible correlation within reporting physician. The type of regression model varied according to the type of outcome of the dependent variable, with logistic regression performed for binary outcomes, negative binomial regression for frequency counts, linear regression for numerical outcomes, and generalized linear modeling with log link and gamma family for cost data (Supplementary Table 1).

Analyses were repeated using propensity score methods as a sensitivity test. Patient were grouped according to the presence of agitation symptoms, with patients having 0 symptoms considered not agitated, and those having $\geq 2$ symptoms considered agitated. Groups were matched on age, gender, time since diagnosis, MMSE score, and number of ADLs needing help with. The propensity score was estimated using a logistic regression model with 1:1 matching, with replacement and allowing for ties. Balance was assessed by calculating standardized mean differences (SMDs); an SMD between $-10 \%$ and $10 \%$ (not inclusive) was taken to be indicative of adequate balance. The treatment effect was computed by taking the average of the difference between the observed and potential outcomes for each patient. The Abadie-Imbens standard error, and the corresponding test statistic and $p$-value were calculated. All analyses were conducted in Stata v16.0 [20].

\section{Ethics}

Data collection was undertaken in line with European Pharmaceutical Marketing Research Association guidelines and as such it does not require ethics committee approval or participant consent. Each survey was performed in full accordance with relevant legislation at the time of data collection, including the US Health Insurance Portability and Accountability Act 1996 and Health Information Technology for Economic and Clinical Health Act legislation.

\section{RESULTS}

\section{Physicians}

A total of 150 physicians contributed to the dementia DSP database, including $20(33 \%)$ PCPs, 59 (39\%) neurologists, $20(13 \%)$ geriatricians, $20(13 \%)$ psychiatrists, and $1(0.7 \%)$ psycho-geriatrician. The majority of physicians $(88 ; 59 \%)$ were both hospitaland office-based, with 61 (41\%) physicians based exclusively at a hospital and $1(0.7 \%)$ at an office.

\section{Patients}

Data were analyzed for 1,349 patients; 693 (48.6\%) patients displayed $\geq 1$ symptom of agitation and $656(51.4 \%)$ patients displayed no agitation symptoms. Agitated patients were slightly older than non-agitated patients and were less likely to be Caucasian and working. Fewer agitated than non-agitated patients were living with their spouse/partner or alone, and a slightly higher proportion of agitated than non-agitated patients lived in a nursing home due to their dementia. Patients experiencing agitation tended to be at a more severe stage of dementia, as perceived by the physician, than those not experiencing agitation, and the most recent MMSE score was lower for agitated than non-agitated patients (Table 1).

Two symptoms of agitation (agitation and irritability/lability) were reported for $>40 \%$ of agitated patients. The least commonly reported symptom $(<10 \%$ of agitated patients) was aberrant motor behavior. No symptom was reported to be severe in $>10 \%$ of patients (Table 1 ). 
Table 1

Patient demographic and clinical characteristics

\begin{tabular}{|c|c|c|c|c|}
\hline & $\begin{array}{c}\text { Total } \\
(N=1,349)\end{array}$ & $\begin{array}{l}\text { Non-agitated } \\
(N=656)\end{array}$ & $\begin{array}{l}\text { Agitated } \\
(N=693)\end{array}$ & $p$ \\
\hline \multicolumn{5}{|l|}{$\overline{\text { Age, } y}$} \\
\hline$n$ & 1349 & 656 & 693 & \multirow[t]{3}{*}{0.0307} \\
\hline Mean (SD) & $75.5(9.0)$ & $75.0(8.8)$ & $76.0(9.1)$ & \\
\hline Range & 50,90 & 50,90 & 50,90 & \\
\hline \multicolumn{5}{|l|}{ Sex, $n(\%)$} \\
\hline$n$ & 1346 & 655 & 691 & \multirow[t]{3}{*}{0.3254} \\
\hline Male & $625(46)$ & $295(45)$ & $330(48)$ & \\
\hline Female & $721(54)$ & $360(55)$ & $361(52)$ & \\
\hline \multicolumn{5}{|l|}{ Ethnicity, $n(\%)$} \\
\hline$n$ & 1347 & 654 & 693 & \multirow[t]{5}{*}{0.0014} \\
\hline White/Caucasian & $976(73)$ & $500(77)$ & $476(69)$ & \\
\hline African American & $186(14)$ & $70(11)$ & $116(17)$ & \\
\hline Hispanic/Latino & $99(7)$ & $51(8)$ & $48(7)$ & \\
\hline Other & $86(6)$ & $33(5)$ & $53(8)$ & \\
\hline \multicolumn{5}{|l|}{ Employment status, $n(\%)$} \\
\hline$n$ & 1327 & 644 & 683 & \multirow{7}{*}{0.0007} \\
\hline Working full-time & $53(4)$ & $34(5)$ & $19(3)$ & \\
\hline Working part-time & $46(4)$ & $34(5)$ & $12(2)$ & \\
\hline Homemaker & $129(10)$ & $61(10)$ & $68(10)$ & \\
\hline Student & $4(0.3)$ & $3(0.5)$ & $1(0.1)$ & \\
\hline Retired & $1014(76)$ & $480(75)$ & $534(78)$ & \\
\hline Unemployed & $81(6)$ & $32(5)$ & $49(7)$ & \\
\hline \multicolumn{5}{|l|}{ Hospital status, $n(\%)$} \\
\hline$n$ & 1305 & 639 & 666 & \multirow[t]{3}{*}{0.0007} \\
\hline Outpatient & $1226(94)$ & $615(96)$ & $611(92)$ & \\
\hline Inpatient & $79(6)$ & $24(4)$ & $55(8)$ & \\
\hline \multicolumn{5}{|l|}{ Home circumstances, $n(\%)$} \\
\hline$n$ & 1338 & 650 & 688 & \multirow[t]{8}{*}{$<0.0001$} \\
\hline Lives with spouse/partner & $770(58)$ & $410(63)$ & $360(52)$ & \\
\hline Lives with other family & $284(21)$ & $115(18)$ & $169(25)$ & \\
\hline Lives alone & $102(8)$ & $70(11)$ & $32(5)$ & \\
\hline Nursing home & $121(9)$ & $30(5)$ & $91(13)$ & \\
\hline Sheltered housing & $31(2)$ & $10(2)$ & $21(3)$ & \\
\hline Lives with friends & $9(1)$ & $3(0.5)$ & $6(1)$ & \\
\hline Other & $21(2)$ & $12(2)$ & $9(1)$ & \\
\hline \multicolumn{5}{|c|}{ Reason for living in a nursing home, $n(\%)$} \\
\hline$n$ & 120 & 29 & 91 & \multirow[t]{3}{*}{0.0232} \\
\hline Dementia & $104(87)$ & $21(72)$ & $83(91)$ & \\
\hline Other & $16(13)$ & $8(28)$ & $8(9)$ & \\
\hline \multicolumn{5}{|l|}{ Current diagnosis, $n(\%)$} \\
\hline$n$ & 1205 & 585 & 620 & \multirow[t]{9}{*}{$<0.0001$} \\
\hline MCI & $237(20)$ & $154(26)$ & $83(13)$ & \\
\hline Amnestic MCI & $13(1)$ & $12(2)$ & $1(0.2)$ & \\
\hline Pre-dementia AD & $84(7)$ & $43(7)$ & $41(7)$ & \\
\hline Prodromal AD & 49 (4) & $28(5)$ & $21(3)$ & \\
\hline $\mathrm{AD}$ & $649(54)$ & $271(46)$ & $37(61)$ & \\
\hline Early onset AD & $106(9)$ & $54(9)$ & $52(8)$ & \\
\hline Mixed vascular dementia/AD & $61(5)$ & $19(3)$ & $42(7)$ & \\
\hline Other & $6(1)$ & $4(1)$ & $2(0.3)$ & \\
\hline \multicolumn{5}{|c|}{ Physician-perceived dementia stage, $n(\%)$} \\
\hline$n$ & 1340 & 651 & 689 & $<0.0001$ \\
\hline MCI & $250(19)$ & $177(27)$ & $73(11)$ & \\
\hline Mild & $473(35)$ & $270(42)$ & $203(30)$ & \\
\hline Moderate & $482(36)$ & $183(28)$ & $299(43)$ & \\
\hline Severe & $135(10)$ & $21(3)$ & $114(17)$ & \\
\hline Most recent MMSE score & & & & \\
\hline$n$ & 1116 & 542 & 574 & $<0.0001$ \\
\hline Mean (SD) & $20.5(5.7)$ & $22.0(5.4)$ & $19.2(5.7)$ & \\
\hline Range & 0,30 & 0,30 & 0,30 & \\
\hline
\end{tabular}


Table 1

(Continued)

\begin{tabular}{|c|c|c|c|c|}
\hline & $\begin{array}{c}\text { Total } \\
(N=1,349)\end{array}$ & $\begin{array}{l}\text { Non-agitated } \\
\quad(N=656)\end{array}$ & $\begin{array}{l}\text { Agitated } \\
(N=693)\end{array}$ & $p$ \\
\hline \multicolumn{5}{|c|}{ Agitation symptom severity ${ }^{a}$} \\
\hline \multicolumn{5}{|c|}{ Aggression, $n(\%)$} \\
\hline None & N/A & N/A & $511(73.7)$ & $<0.0001$ \\
\hline Mild & & & $75(10.8)$ & \\
\hline Moderate & & & $77(11.1)$ & \\
\hline Severe & & & $30(4.3)$ & \\
\hline \multicolumn{5}{|c|}{ Disinhibition, $n(\%)$} \\
\hline None & N/A & N/A & $567(81.8)$ & $<0.0001$ \\
\hline Mild & & & $47(6.8)$ & \\
\hline Moderate & & & $57(8.2)$ & \\
\hline Severe & & & $22(3.2)$ & \\
\hline \multicolumn{5}{|c|}{ Wandering, $n(\%)$} \\
\hline None & N/A & N/A & $526(75.9)$ & $<0.0001$ \\
\hline Mild & & & $82(11.8)$ & \\
\hline Moderate & & & $53(7.6)$ & \\
\hline Severe & & & $32(4.6)$ & \\
\hline \multicolumn{5}{|l|}{ Agitation, $n(\%)$} \\
\hline None & N/A & N/A & $373(53.8)$ & $<0.0001$ \\
\hline Mild & & & $119(17.2)$ & \\
\hline Moderate & & & $162(23.4)$ & \\
\hline Severe & & & $39(5.6)$ & \\
\hline \multicolumn{5}{|c|}{ Irritability/Lability, $n(\%)$} \\
\hline None & N/A & N/A & $403(58.2)$ & $<0.0001$ \\
\hline Mild & & & $105(15.2)$ & \\
\hline Moderate & & & $155(22.4)$ & \\
\hline Severe & & & $30(4.3)$ & \\
\hline \multicolumn{5}{|c|}{ Aberrant motor behavior, $n(\%)$} \\
\hline None & N/A & N/A & $628(92.1)$ & $<0.0001$ \\
\hline Mild & & & $24(3.5)$ & \\
\hline Moderate & & & $22(3.2)$ & \\
\hline Severe & & & $9(1.3)$ & \\
\hline \multicolumn{5}{|c|}{ Social interaction problems, $n(\%)$} \\
\hline None & N/A & N/A & $422(62.3)$ & $<0.0001$ \\
\hline Mild & & & $94(13.6)$ & \\
\hline Moderate & & & $121(17.5)$ & \\
\hline Severe & & & $46(6.6)$ & \\
\hline \multicolumn{5}{|c|}{ Agitation symptoms severity score } \\
\hline Mean (SD) & N/A & N/A & $3.6(3.1)$ & $<0.0001$ \\
\hline Range & & & 1,21 & \\
\hline
\end{tabular}

${ }^{a}$ Seven physician-reported symptoms (including agitation) were considered to be indicative of agitation, based on the IPA definition of agitation ${ }^{9}$. AD, Alzheimer's disease; IPA, International Psychogeriatric Association; MCI, mild cognitive impairment; MMSE, Mini-Mental State Examination; SD, standard deviation.

\section{Caregiver presence}

Physician-reported data on caregiver presence were available for 1,341 patients; $442(67.8 \%)$ nonagitated and $594(86.2 \%)$ agitated patients required a caregiver (professional or non-professional); of these, $100(15.3 \%)$ non-agitated patients and $248(36.0 \%)$ agitated patients needed a professional caregiver.

Regression analysis showed no difference in the proportion of patients with a caregiver based on agitation score $(p=0.329)$, but the proportion of patients with a professional caregiver increased with increasing agitation score $(p=0.006)$.
Sensitivity analysis using $\geq 2$ symptoms to define an agitated patient, following propensity score matching, confirmed that agitated patients were more likely than non-agitated patients to have a professional caregiver $(p=0.015)$.

\section{$H C R U$}

Based on descriptive data, physicians reported agitated patients requiring more hours/week of caregiving (professional or informal/non-professional) than non-agitated patients. The number of consultations 
Table 2

Impact of agitation on HCRU

\begin{tabular}{|c|c|c|c|c|}
\hline & $\begin{array}{c}\text { Total } \\
(N=1,349)\end{array}$ & $\begin{array}{l}\text { Non-agitated } \\
\quad(N=656)\end{array}$ & $\begin{array}{l}\text { Agitated } \\
(N=693)\end{array}$ & $p$ \\
\hline \multicolumn{5}{|c|}{ Non-professional caregiver time/week, hours } \\
\hline$n$ & 1253 & 609 & 644 & \multirow[t]{3}{*}{$<0.0001$} \\
\hline Mean (SD) & $40.8(58.4)$ & $33.3(54.2)$ & $48.0(61.4)$ & \\
\hline Range & 0,280 & 0,280 & 0,224 & \\
\hline \multicolumn{5}{|c|}{ Professional caregiver time/week, hours } \\
\hline$n$ & 1321 & 646 & 675 & \multirow[t]{3}{*}{$<0.0001$} \\
\hline Mean (SD) & $19.1(47.5)$ & $10.6(36.7)$ & $27.2(54.7)$ & \\
\hline Range & 0,175 & 0,168 & 0,175 & \\
\hline \multicolumn{5}{|c|}{ PCP consultations in previous 12 months } \\
\hline$n$ & 1349 & 656 & 693 & \multirow[t]{3}{*}{0.0201} \\
\hline Mean (SD) & $2.1(2.2)$ & $2.0(1.8)$ & $2.2(2.5)$ & \\
\hline Range & 0,30 & 0,13 & 0,30 & \\
\hline \multicolumn{5}{|c|}{ Neurologist consultations in previous 12 months } \\
\hline$n$ & 1349 & 656 & 693 & \multirow[t]{3}{*}{$<0.0001$} \\
\hline Mean (SD) & $1.3(1.5)$ & $1.1(1.3)$ & $1.5(1.7)$ & \\
\hline Range & 0,10 & 0,6 & 0,10 & \\
\hline \multicolumn{5}{|c|}{ Geriatrician consultations in previous 12 months } \\
\hline$n$ & 1349 & 656 & 93 & \multirow[t]{3}{*}{$<0.0001$} \\
\hline Mean (SD) & $0.6(1.6)$ & $0.4(1.2)$ & $0.8(1.9)$ & \\
\hline Range & 0,12 & 0,12 & 0,12 & \\
\hline \multicolumn{5}{|c|}{ Psychiatrist consultations in previous 12 months } \\
\hline$n$ & 1349 & 656 & 693 & \multirow[t]{3}{*}{$<0.0001$} \\
\hline Mean (SD) & $0.8(2.1)$ & $0.5(1.5)$ & $1.1(2.5)$ & \\
\hline Range & 0,20 & 0,15 & 0,20 & \\
\hline \multicolumn{5}{|c|}{ Psycho-geriatrician consultations in previous 12 months } \\
\hline$n$ & 1349 & 656 & 693 & \multirow[t]{3}{*}{$<0.0001$} \\
\hline Mean (SD) & $0.1(0.9)$ & $0.0(0.3)$ & $0.2(1.2)$ & \\
\hline Range & 0,16 & 0,4 & 0,16 & \\
\hline \multicolumn{5}{|c|}{ Memory specialist consultations in previous 12 months } \\
\hline$n$ & 1349 & 656 & 693 & \multirow[t]{3}{*}{0.7591} \\
\hline Mean (SD) & $0.0(0.3)$ & $0.0(0.2)$ & $0.0(0.3)$ & \\
\hline Range & 0,5 & 0,4 & 0,5 & \\
\hline \multicolumn{5}{|c|}{ Total HCP consultations in previous 12 months } \\
\hline$n$ & 1349 & 656 & 693 & \multirow[t]{3}{*}{$<0.0001$} \\
\hline Mean (SD) & $5.4(4.9)$ & $4.3(3.0)$ & $6.5(6.0)$ & \\
\hline Range & 0,52 & 0,29 & 0,52 & \\
\hline \multicolumn{5}{|l|}{ Institutionalized } \\
\hline$n$ & 1336 & 649 & 687 & \multirow[t]{2}{*}{$<0.0001$} \\
\hline$n(\%)$ & $103(7.7)$ & $21(3.2)$ & $82(11.9)$ & \\
\hline \multicolumn{5}{|c|}{ Hospitalizations for any reason in previous 12 months } \\
\hline$n$ & 1349 & 656 & 693 & $<0.0001$ \\
\hline Mean (SD) & $0.3(0.7)$ & $0.2(0.6)$ & $0.4(0.9)$ & \\
\hline Range & 0,10 & 0,6 & 0,10 & \\
\hline Hospitalization & & & & \\
\hline$n$ & 1316 & 631 & 685 & 0.0012 \\
\hline Mean (SD) & $0.1(0.4)$ & $0.0(0.3)$ & $0.1(0.4)$ & \\
\hline Range & 0,6 & 0,6 & 0,6 & \\
\hline Spent time on $\mathrm{p}$ & & & & \\
\hline$n$ & 1316 & 631 & 685 & 0.3762 \\
\hline$n(\%)$ & $5(0.4)$ & $1(0.2)$ & $4(0.6)$ & \\
\hline
\end{tabular}

CI, cognitive impairment; HCP, healthcare practitioner; PCP, primary care physician; SD, standard deviation.

with all types of HCPs in the 12 months prior to data collection was higher for agitated than nonagitated patients, although the number of memory specialist consultations was very low for both groups of patients and did not differ between agitated and non-agitated patients. A higher proportion of agitated than non-agitated patients was institutionalized and more hospitalizations, for any cause or due to CI, were reported for patients demonstrating agitation symptoms compared with those not demonstrating 
Table 3

Impact of agitation on current medication

\begin{tabular}{|c|c|c|c|c|}
\hline & $\begin{array}{c}\text { Total } \\
(N=1,349)\end{array}$ & $\begin{array}{c}\text { Non-agitated } \\
(N=656)\end{array}$ & $\begin{array}{l}\text { Agitated } \\
(N=693) \\
\end{array}$ & $p$ \\
\hline \multicolumn{5}{|c|}{ No current treatment } \\
\hline$n$ & 1329 & 644 & 685 & \multirow[t]{2}{*}{$<0.0001$} \\
\hline$n(\%)$ & $263(19.8)$ & $162(25.2)$ & $101(14.7)$ & \\
\hline \multicolumn{5}{|c|}{ Currently receiving acetylcholinesterase inhibitors } \\
\hline$n$ & 1329 & 644 & 685 & \multirow[t]{2}{*}{0.0057} \\
\hline$n(\%)$ & $937(70.5)$ & $431(66.9)$ & $506(73.9)$ & \\
\hline \multicolumn{5}{|c|}{ Currently receiving memantine } \\
\hline$n$ & 1329 & 644 & 685 & \multirow[t]{2}{*}{$<0.0001$} \\
\hline$n(\%)$ & 437 (32.9) & $166(25.8)$ & $271(39.6)$ & \\
\hline \multicolumn{5}{|c|}{ Currently receiving antipsychotics } \\
\hline$n$ & 1329 & 644 & 685 & \multirow[t]{2}{*}{$<0.0001$} \\
\hline$n(\%)$ & $101(7.6)$ & $16(2.5)$ & $166(24.2)$ & \\
\hline \multicolumn{5}{|c|}{ Currently receiving antidepressants } \\
\hline$n$ & 1329 & 644 & 685 & \multirow[t]{2}{*}{$<0.0001$} \\
\hline$n(\%)$ & $233(17.5)$ & $67(10.4)$ & $166(24.2)$ & \\
\hline \multicolumn{5}{|c|}{ Currently receiving benzodiazepines } \\
\hline$n$ & 1329 & 644 & 685 & \multirow[t]{2}{*}{$<0.0001$} \\
\hline$n(\%)$ & $103(7.8)$ & $23(3.6)$ & $76(11.1)$ & \\
\hline
\end{tabular}

agitation symptoms in the 12 months prior to data collection (Table 2).

A higher proportion of non-agitated than agitated patients were currently receiving no treatment, while a higher proportion of agitated than nonagitated patients were receiving acetylcholinesterase inhibitors, memantine, antipsychotics, antidepressants, and benzodiazepines (Table 3 ).

Based on regression analysis (Fig. 1), the level of agitation experienced by patients was observed to be associated with the use of a number of healthcare resources. Within the 12 months prior to data collection, as agitation score increased, so did the number of consultations with psychiatrists $(p=0.001)$, psychogeriatricians $(p<0.001)$, and all HCPs $(p<0.001)$. The proportion of patients institutionalized increased with increasing agitation score $(p=0.004)$. The number of hospitalizations in the 12 months prior to data collection increased with increasing agitation score, whether for any reason or for CI (both $p=0.001$ ). The likelihood of spending time on a psychiatric ward in the previous 12 months was also associated with agitation score $(p=0.035)$. The proportion of patients receiving no treatment decreased with increasing agitation score $(p=0.016)$, while the proportion of patients receiving either an antipsychotic or an antidepressant increased with increasing agitation score (both $p<0.001$ ).

On propensity score analysis, the number of consultations in the past 12 months with psychiatrists $(p=0.024)$, psycho-geriatricians $(p=0.006)$ and all HCPs $(p<0.001)$ was higher in agitated than non-agitated patients. Propensity score analysis also indicated a higher proportion of agitated than non-agitated patients was institutionalized $(p=$ $0.019)$, and that the proportions of patients receiving antipsychotics $(p=0.016)$, antidepressants $(p<$ $0.001)$, and benzodiazepines $(p=0.017)$ were all higher in agitated than non-agitated patients.

\section{Healthcare costs}

Mean (standard deviation) total direct healthcare costs in the 12 months prior to data collection were $\$ 9,243(\$ 17,725)$ for non-agitated patients and $\$ 20,041(\$ 26,495)$ for agitated patients (Supplementary Table 2).

Based on regression analysis (Fig. 2), the level of agitation experienced by patients was observed to be associated with the cost of hospitalizations ( $p=$ $0.003)$, HCP consultations $(p<0.001)$, scans $(p=$ $0.001)$, and total direct healthcare costs $(p<0.001)$ in the 12 months prior to data collection. The costs of professional caregiving ( $p=0.880)$, nursing homes $(p=0.528)$, and treatment $(p=0.266)$, however, were not correlated with agitation score.

Propensity score sensitivity analysis indicated that the cost of professional caregiving, HCP consultations and scans in the previous 12 months were higher in agitated than non-agitated patients when agitation was defined as $\geq 2$ symptoms (all $p<0.001$ ). 

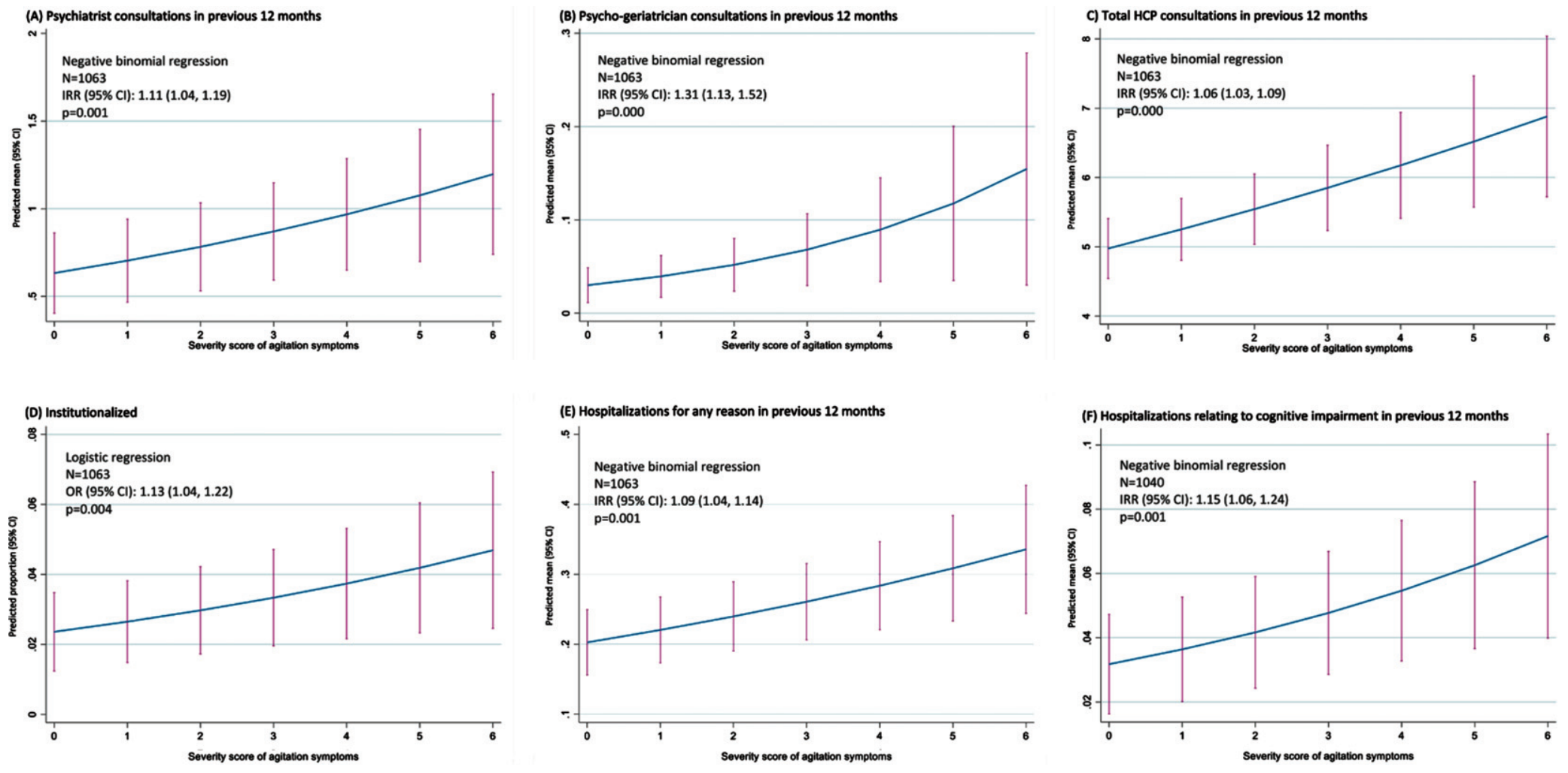

Fig. 1. Impact of agitation score on $\mathrm{HCRU}$ - regression analysis. CI, confidence interval; $\mathrm{HCP}$, healthcare professional; IRR, incidence rate ratio; OR, odds ratio. 


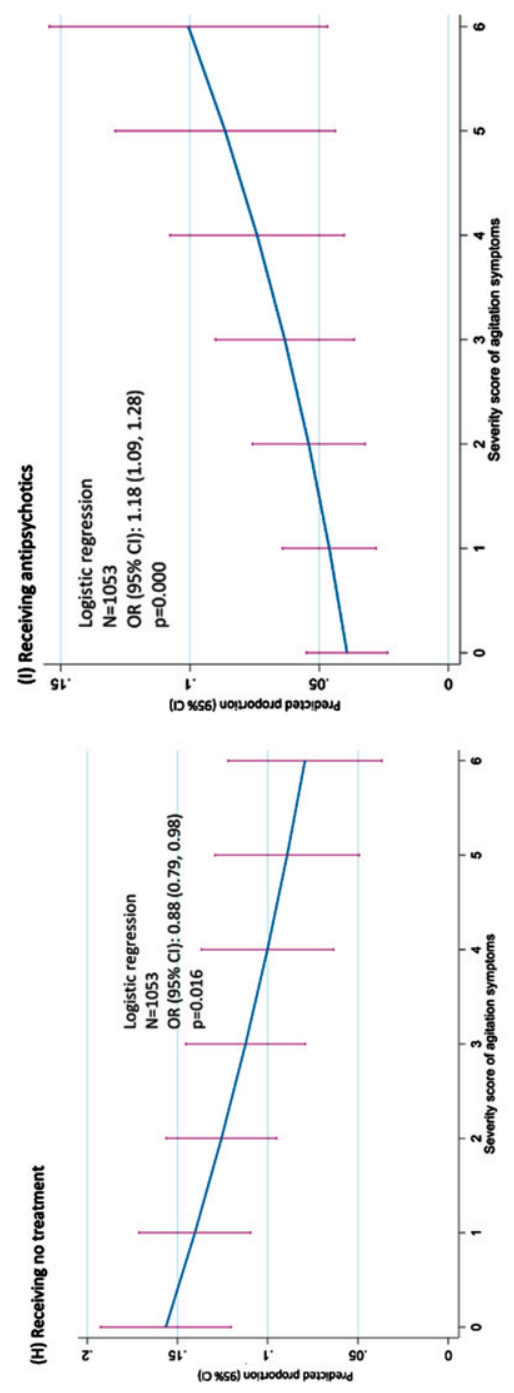

نَّ
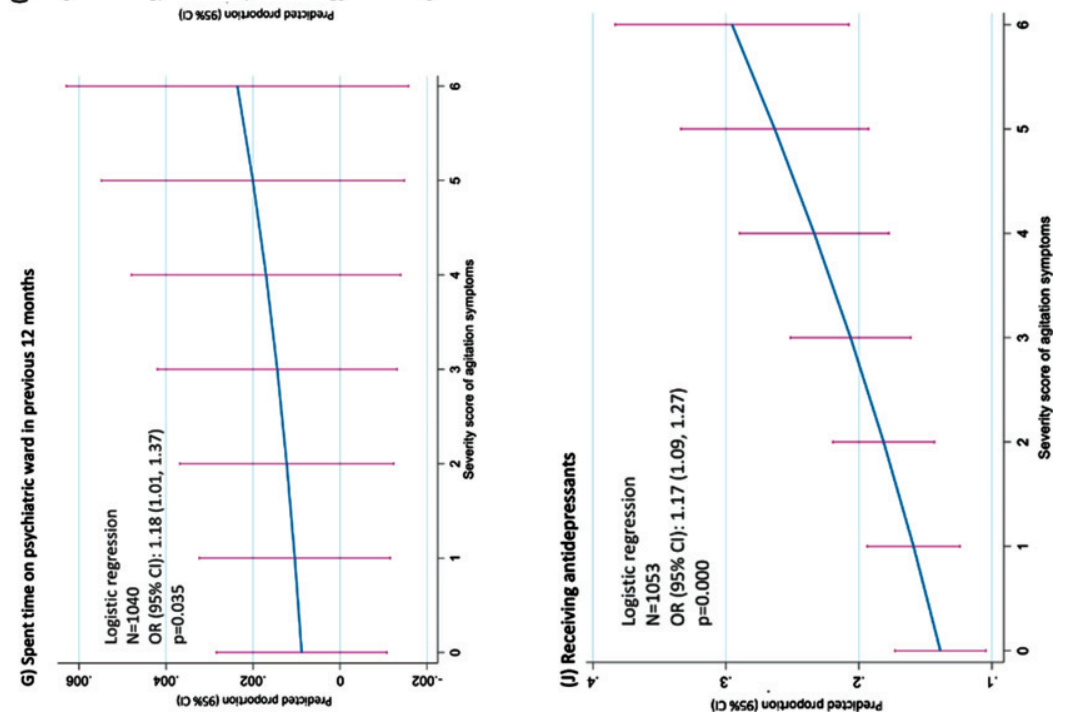

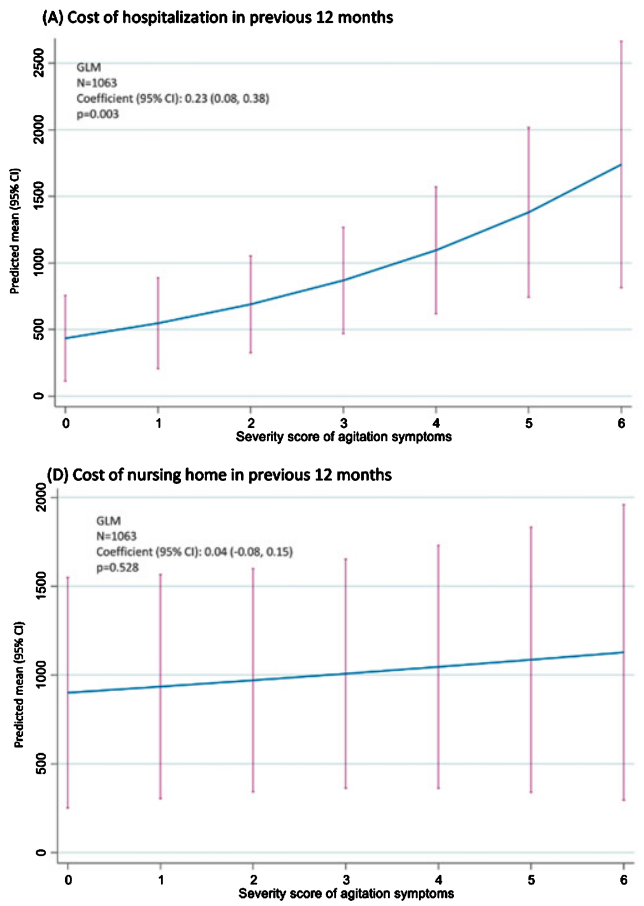

(G) Total direct healthcare costs in previous 12 months

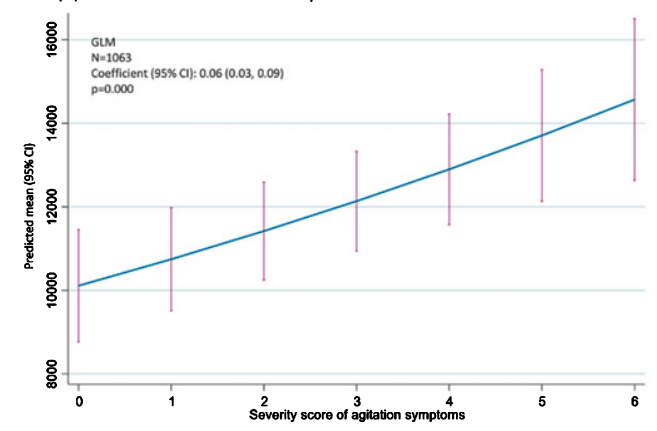

(B) Cost of professional caregiver in previous 12 months

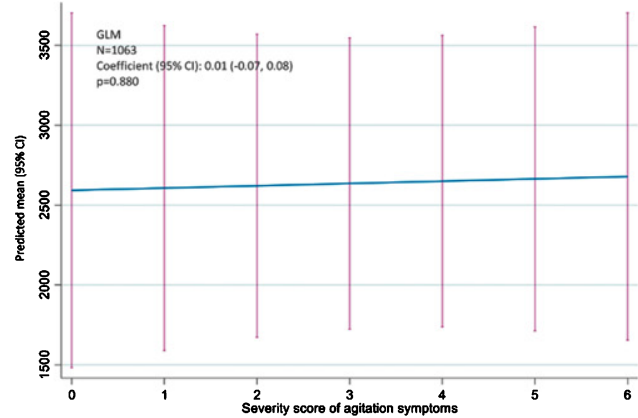

(E) Cost of treatment in previous 12 months

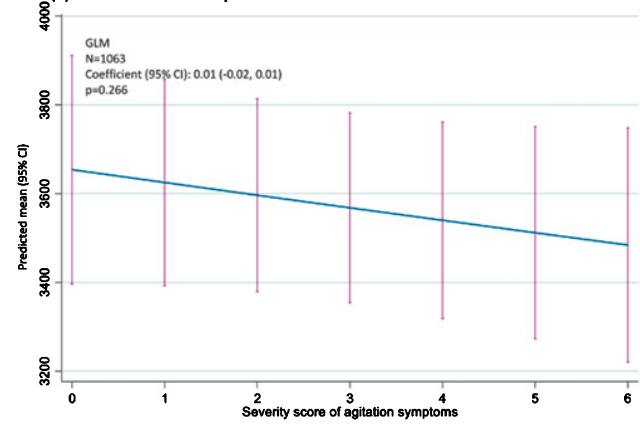

Fig. 2. Impact of agitation score on healthcare costs - regression analysis. CI, confidence interval; GLM, generalized linear modeling; HCP, healthcare professional. 


\section{DISCUSSION}

This study demonstrated the incremental impact and burden of agitation in patients with dementia on patients, HCRU, and healthcare costs using real-world US data. Patients showing symptoms of agitation were perceived by their physicians to be at a more severe stage of dementia and were more likely be diagnosed with $\mathrm{AD}$ rather than mild CI compared with patients without agitation symptoms. This reflects findings reported in the literature, including observational studies from the US, the Netherlands, Australia, and Japan, showing agitation to be associated with dementia severity [21-24].

There was clear evidence of agitation adding to the presence of a caregiver (professional or informal/nonprofessional), with the proportion of patients with a caregiver and the number of caregiving hours higher in agitated than non-agitated patients, and the proportion of patients with professional caregivers correlated with agitation score.

We also observed HCRU and healthcare costs in patients with dementia to be associated with agitation. The total number of consultations with all HCPs, psychiatrists, and psycho-geriatricians in the previous 12 months were correlated with the agitation score. The likelihood of being institutionalized was more than three times higher in agitated than non-agitated patients, and the proportion of institutionalized patients increased with increasing agitation level. The number of hospitalizations (for any cause or due to $\mathrm{CI}$ ) in the previous 12 months was related to agitation score, as was the proportion of patients who spent time on a psychiatric ward.

There are a few published studies on the impact of agitation on HCP consultations, institutionalizations, or hospitalizations in patients with dementia. A crosssectional study of patients in nursing homes in the Netherlands indicated that agitation might increase consultations with psychiatrists, as we observed, as agitation was reported to be the primary reason for a psychiatric consultation [25]. Agitation in adults aged $\geq 71$ years with CI was also shown to be associated with a significantly increased risk of institutionalization in a Japanese study [26].

We observed the likelihood of receiving no treatment was lower in agitated than non-agitated patients and decreased with increasing agitation score, that more agitated than non-agitated patients were receiving treatment with acetylcholinesterase inhibitors, memantine, antipsychotics, antidepressants, and benzodiazepines, and that the proportion of patients receiving an antipsychotic or antidepressant increased with increasing agitation score. There is limited evidence of efficacy and a risk of adverse effects for pharmacologic agents in the management of agitation symptoms in dementia; consequently, drug therapy should be considered only if symptoms are severely distressing for patients or caregivers $[9,27]$. However, a Cochrane review reported the antidepressants sertraline and citalopram to be associated with a reduction in symptoms of agitation when compared to placebo [28]; meanwhile, brexpiprazole, an atypical antipsychotic, has been shown to have the potential to improve agitation in $\mathrm{AD}$ compared with placebo [29]. A sequential treatment algorithm with risperidone, aripiprazole or quetiapine, carbamazepine, citalopram, gabapentin, and prazosin has been proposed [30].

We observed increasing healthcare costs to be associated with increasing agitation. Cross-sectional data from a large patient cohort from eight European countries showed a significant difference in cost of care between dementia patients experiencing and not experiencing agitation, in both home care and institutional long-term care settings [31]. A prospective cohort study of data from UK patients with $\mathrm{AD}$ showed health and social care costs to vary significantly between patients with and without agitation, with the authors calculating an excess cost associated with agitation of $£ 2$ billion/year for all $\mathrm{AD}$ patients in the UK [32]. An analysis of a population-based sample of patients with dementia in the US also showed an increase in agitation/aggression led to increased costs of informal care [33].

Given the association of agitation with more severe/advanced dementia that we observed, and that has been reported in the literature [21-24], it might be speculated that underlying disease severity is driving the higher HCRU and healthcare cost that we noted in patients with agitation. However, as both disease severity (assessed by the MMSE) and time since diagnosis were covariates in the regression analyses, it would appear that the presence of agitation is an independent factor in the higher economic burden seen in the group of patients experiencing agitation symptoms.

Our study had a number of potential limitations. The DSP data collection included the next nine consecutively consulting patients, resulting in a pseudorandom, rather than truly random, study sample. As with all surveys of this type, the methodology relied on accurate reporting by physicians; missing data were to be expected and may have influenced results. 
This was a point-in-time rather than a longitudinal survey and data may have been used to assess the association between factors but not causality. The survey was restricted to physician office and hospital settings, excluding residential care facilities; more severe dementia cases might not have been included in the physicians' consulting practices, and hence would not have been reflected in this sample. It is likely that healthcare costs varied by region, but costs were calculated based on a number of national data sources; this might have resulted in the impact of agitation on healthcare costs being under- or overestimated. In our analysis, agitation was defined to reflect elements of the IPA consensus on the definition of agitation [7] as closely as possible given this was a retrospective analysis, and therefore utilized data available in the data source. The inclusion of additional symptoms, or the exclusion of any of the symptoms used in our analysis, might result in the re-classification of some patients from agitated to non-agitated, or vice versa. Finally, it is important to consider that the agitation scoring method gave equal weighting to all symptoms and assumed a linear relationship between mild, moderate, and severe symptom severity. While acknowledging these limitations, a substantial body of data from a representative population of almost 1,500 patients with varying degrees of dementia in the real-world setting in the US was included in the analysis, providing valuable insight into the incremental burden of agitation in dementia.

Our data demonstrated an association between agitation in patients with dementia with increased HCRU and healthcare costs. There remains a largely unmet need for effective therapeutic interventions to address neuropsychiatric symptoms, including agitation, in dementia, with the potential to alleviate patient suffering and societal costs.

\section{ACKNOWLEDGMENTS}

This work was funded by Otsuka Pharmaceutical Development \& Commercialization, Inc. and Lundbeck, LLC.

Medical writing support under the guidance of the authors was provided by Carole Evans, $\mathrm{PhD}$, on behalf of Adelphi Real World, and was funded by Otsuka Pharmaceutical Development \& Commercialization, Inc. and Lundbeck LLS, in accordance with Good Publication Practice guidelines (Ann Intern Med 163, 461-464, 2015).
Authors' disclosures available online (https:// www.j-alz.com/manuscript-disclosures/21-0105r1).

\section{SUPPLEMENTARY MATERIAL}

The supplementary material is available in the electronic version of this article: https://dx.doi.org/ 10.3233/JAD-210105.

\section{REFERENCES}

[1] Amr M, El-Gilany AH, Sallam K, Shams T (2014) Characteristics of patients with dementia attended in a tertiary outpatient clinic in Eastern Region, Saudi Arabia. J Psychiatry 17, 6 .

[2] Archer N, Brown RG, Reeves SJ, Boothby H, Nicholas H, Foy C, Williams J, Lovestone S (2007) Premorbid personality and behavioral and psychological symptoms in probable Alzheimer disease. Am J Geriatr Psychiatry 15, 202-213.

[3] Lanctôt KL, Amatniek J, Ancoli-Israel S, Arnold SE, Ballard C, Cohen-Mansfield J, Ismail Z, Lyketsos C, Miller DS, Musiek E, Osorio RS, Rosenberg PB, Satlin A, Steffens D, Tariot P, Bain LJ, Carrillo MC, Hendrix JA, Jurgens H, Boot B (2017) Neuropsychiatric signs and symptoms of Alzheimer's disease: New treatment paradigms. Alzheimers Dement (N Y) 5, 440-449.

[4] Van der Mussele S, Le Bastard N, Saerens J, Somers N, Mariën P, Goeman J, De Deyn PP, Engelborghs S (2015) Agitation-associated behavioral symptoms in mild cognitive impairment and Alzheimer's dementia. Aging Ment Health 19, 247-257.

[5] Anatchkova M, Brooks A, Swett L, Hartry A, Duffy RA, Baker RA, Hammer-Helmich L, Sanon Aigbogun M (2019) Agitation in patients with dementia: A systematic review of epidemiology and association with severity and course. Int Psychogeriatr 11, 1-14.

[6] Sachs GS (2006) A review of agitation in mental illness: Burden of illness and underlying pathology. J Clin Psychiatry 67(Suppl 10), 5-12.

[7] Cummings J, Mintzer J, Brodaty H, Sano M, Banerjee S, Devanand DP, Gauthier S, Howard R, Lanctôt K, Lyketsos CG, Peskind E, Porsteinsson AP, Reich E, Sampaio C, Steffens D, Wortmann M, Zhong K; International Psychogeriatric Association (2015) Agitation in cognitive disorders: International Psychogeriatric Association provisional consensus clinical and research definition. Int Psychogeriatr 27, 7-17.

[8] Rosenberg PB, Nowrangi MA, Lyketsos CG (2015) Neuropsychiatric symptoms in Alzheimer's disease: What might be associated brain circuits? Mol Aspects Med 43-44, 25-37.

[9] Reus VI, Fochtmann LJ, Eyler AE, Hilty DM, HorvitzLennon M, Jibson MD, Lopez OL, Mahoney J, Pasic J, Tan ZS, Wills CD, Rhoads R, Yager J (2016) The American Psychiatric Association Practice Guideline on the use of antipsychotics to treat agitation or psychosis in patients with dementia. Am J Psychiatry 173, 543-546.

[10] McDermott CL, Gruenewald DA (2019) Pharmacologic management of agitation in patients with dementia. Curr Geriatr Rep 8, 1-11.

[11] Anatchkova M, Brooks A, Swett L, Harty A, Duffy R, Baker R, Hammer-Helmich L, Sanon Aigbogun M (2017) 
Economic burden of agitation in Alzheimer's disease: A systematic literature review. Presented at ISPOR 22nd Annual International Meeting, May 20-24, 2017, Boston, MA.

[12] Anderson P, Benford M, Harris N, Karavali M, Piercy J (2008) Real-world physician and patient behaviour across countries: Disease-Specific Programmes - a means to understand. Curr Med Res Opin 24, 3063-3072.

[13] Ritchie CW, Black CM, Khandker RK, Wood R, Jones E, Hu X, Ambegaonkar BM (2018) Quantifying the diagnostic pathway for patients with cognitive impairment: Real-world data from seven European and North American countries. $J$ Alzheimers Dis 62, 457-466.

[14] American Academy of Neurology (2018) Medicare Physician Fee Schedule. https://www.aan.com/siteassets/ home-page/tools-and-resources/practicing-neurologistadministrators/billing-and-coding/medicare-fee-for-serv ice/18medicarevalues_tr.pdf, Accessed on October 7, 2020.

[15] Centers for Disease Control and Prevention (2015) National Ambulatory Medical Care Survey: 2015 State and National Summary Tables. https://www.cdc.gov/nchs/data/ahcd/ namcs_summary/2015_namcs_web_tables.pdf, Accessed on October 7, 2020.

[16] Centers for Medicare \& Medicaid Services (2020) Physician Fee Schedule Look-Up Tool. https://www.cms.gov/ apps/physician-fee-schedule/search/search-criteria.aspx, Accessed on October 7, 2020.

[17] Agency for Healthcare Research and Quality (2020) HCUPnet Healthcare Cost and Utilization Project. https:// hcupnet.ahrq.gov/\#setup, Accessed on October 7, 2020.

[18] New Choice Health (2020) https://www.newchoicehealth. com, Accessed on October 7, 2020.

[19] US Department of Veterans Affairs (2020) Pharmaceutical pricing data for all VA National Acquisition Center programs. https://www.va.gov/opal/nac/fss/pharmPrices.asp, Accessed on October 7, 2020.

[20] StataCorp (2019) Stata Statistical Software: Release 16. StataCorp LLC, College Station, TX.

[21] Brodaty H, Connors MH, Xu J, Woodward M, Ames D; PRIME study group (2015) The course of neuropsychiatric symptoms in dementia: A 3-year longitudinal study. $J$ Am Med Dir Assoc 16, 380-387.

[22] Zahodne LB, Ornstein K, Cosentino S, Devanand DP, Stern Y (2015) Longitudinal relationships between Alzheimer disease progression and psychosis, depressed mood, and agitation/aggression. Am J Geriatr Psychiatry 23, 130-140.

[23] Tanaka H, Hashimoto M, Fukuhara R, Ishikawa T, Yatabe Y, Kaneda K, Yuuki S, Honda K, Matsuzaki S, Tsuyuguchi A, Hatada Y, Ikeda M (2015) Relationship between dementia severity and behavioural and psychological symptoms in early-onset Alzheimer's disease. Psychogeriatrics 15, 242-247.
[24] Veldwijk-Rouwenhorst AE, Smalbrugge M, Wetzels R, Bor H, Zuidema SU, Koopmans RTCM, Gerritsen DL (2017) Nursing home residents with dementia and very frequent agitation: A particular group. Am J Geriatr Psychiatry 25, 1339-1348.

[25] Kat MG, Zuidema SU, van der Ploeg T, Kalisvaart KJ, van Gool WA, Eikelenboom P, de Jonghe JF (2008) Reasons for psychiatric consultation referrals in Dutch nursing home patients with dementia: A comparison with normative data on prevalence of neuropsychiatric symptoms. Int J Geriatr Psychiatry 23, 1014-1019.

[26] Okura T, Plassman BL, Steffens DC, Llewellyn DJ, Potter GG, Langa KM (2011) Neuropsychiatric symptoms and the risk of institutionalization and death: The aging, demographics, and memory study. J Am Geriatr Soc 59, 473-481.

[27] Deardorff WJ, Grossberg GT (2019) Behavioral and psychological symptoms in Alzheimer's dementia and vascular dementia. Handb Clin Neurol 165, 5-32.

[28] Seitz DP, Adunuri N, Gill SS, Gruneir A, Herrmann N, Rochon P (2011) Antidepressants for agitation and psychosis in dementia. Cochrane Database Syst Rev 16, CD008191.

[29] Grossberg GT, Kohegyi E, Mergel V, Josiassen MK, Meulien D, Hobart M, Slomkowski M, Baker RA, McQuade RD, Cummings JL (2020) Efficacy and safety of brexpiprazole for the treatment of agitation in Alzheimer's dementia: Two 12-week, randomized, double-blind, placebo-controlled trials. Am J Geriatr Psychiatry 28, 383-400.

[30] Davies SJ, Burhan AM, Kim D, Gerretsen P, Graff-Guerrero A, Woo VL, Kumar S, Colman S, Pollock BG, Mulsant BH, Rajji TK (2018) Sequential drug treatment algorithm for agitation and aggression in Alzheimer's and mixed dementia. J Psychopharmacol 32, 509-523.

[31] Costa N, Wübker A, De Mauléon A, Zwakhalen SMG, Challis D, Leino-Kilpi H, Hallberg IR, Stephan A, Zabalegui A, Saks K, Molinier L, Wimo A, Vellas B, Sauerland D, Binot I, Soto ME; RightTimePlaceCare consortium (2018) Costs of care of agitation associated with dementia in 8 European countries: Results from the RightTimePlaceCare Study. $J$ Am Med Dir Assoc 19, 95.e1-95.e10.

[32] Morris S, Patel N, Baio G, Kelly L, Lewis-Holmes E, Omar RZ, Katona C, Cooper C, Livingston G (2015) Monetary costs of agitation in older adults with Alzheimer's disease in the UK: Prospective cohort study. BMJ Open 13, e007382.

[33] Rattinger GB, Sanders CL, Vernon E, Schwartz S, Behrens S, Lyketsos CG, Tschanz JT (2019) Neuropsychiatric symptoms in patients with dementia and the longitudinal costs of informal care in the Cache County population. Alzheimers Dement (N Y) 5, 81-88. 